\title{
Chiral heterocyclic ligands. XI. Self-assembly and X-ray crystal structures of chiral silver coordination polymers of (S)-(-)-nicotine.
}

\author{
William Lewis and Peter J. Steel* \\ Chemistry Department, University of Canterbury, Christchurch 8020, New Zealand
}

Three chiral coordination polymers have been prepared by reaction of (S)-(-)-nicotine with silver(I) salts. X-Ray crystal structure determinations revealed that these all contain polymer chains in which the nicotine molecule acts as a bridging ligand between four-coordinate silver atoms. In one case additional bridging by nitrate anions leads to a three-dimensional network structure.

Keywords: Coordination polymer; Silver; Chiral; Nicotine; Crystal structure

\section{INTRODUCTION}

Metallosupramolecular chemistry involves the reactions of bridging organic ligands with appropriate metal-containing precursors for the construction of a diverse range of supramolecular architectures [1]. Within this context coordination polymers have proved particularly popular [2-5]. These are readily prepared from combinations of metals and ligands and exist as one-, two- or three-dimensional polymeric assemblies. The simplest such coordination polymers are linear one-dimensional examples, which are constructed from rigid linear bridging ligands (such as 4,4'-bipyridine) and linear metal connectors. For this purpose silver(I) salts have been extensively used [6,7]. Higher-level bridging components lead to more complex two- and three-dimensional networks which may possess porous internal cavities [813] or involve complex interpenetrated nets [14-18].

Most work in this area has simply involved the synthesis and characterisation of such coordination polymers. More recently, attention has moved towards finding useful applications for such compounds based on functional properties displayed by these materials [19-21]. One such property that has attracted much interest is in the area of non-linear optics (NLO) [22-27]. Certain coordination polymers exhibit interesting NLO properties that may have useful applications in various areas of material science. An important requirement for NLO properties 
is that the material be noncentrosymmetric. Various approaches have been employed in the design of homochiral coordination polymers. These include the use of chiral metal precursors [28], chiral ligands [29-34], chiral counterions [35,36], helicate formation [37-41] and even the use of spontaneous resolution of achiral materials [42-45].

We believe that the simplest approach is to use chiral bridging ligands and have recently reported the synthesis and study of some $\mathrm{C}_{2}$-symmetric chiral bridging ligands derived from the readily available monoterpene $(+)$-camphor $[46,47]$. Based on our extensive experience in the design and synthesis of new heterocyclic ligands [48,49], we have found that the best bridging ligands are either highly symmetrical (with all binding domains identical) or highly unsymmetrical (with sterically and electronically very different binding domains). Bridging ligands with similar, but slightly different, metal-binding sites tend to struggle to faithfully align themselves in the course of a supramolecular assembly process. This in turn leads to complex isomeric mixtures of products.

(S)-(-)-Nicotine (1) is a readily available chiral alkaloid obtained from the tobacco plant. It contains two potential metal-binding sites, a pyridine nitrogen and a tertiary-amino (pyrrolidine) nitrogen, which are structurally and electronically very different and hence nicotine is a potentially useful bridging ligand. Surprisingly little coordination chemistry has been reported for nicotine [50-56]. A number of mononuclear complexes have been reported in which nicotine is bound only through the pyridine nitrogen. The only structurally characterised example in which nicotine acts as a bridging ligand is a mercuric chloride complex [57]. In continuation of our work on silver complexes of heterocyclic ligands [58-60], we now report the synthesis and $\mathrm{X}$-ray crystal structures of three chiral silver coordination polymers of $(S)$-(-)-nicotine.

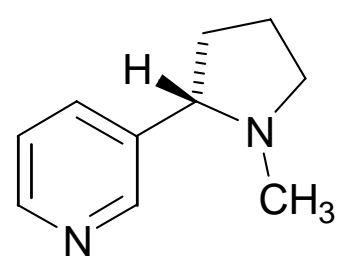

(1)

\section{RESULTS AND DISCUSSION}

(S)-(-)-Nicotine was reacted with a variety of silver(I) salts under a range of reaction conditions. Crystalline products suitable for X-ray structure determination were obtained from three such reactions. Reaction of equimolar quantities of silver nitrate and nicotine in acetonitrile followed by vapour diffusion of diethyl ether into the reaction mixture furnished a crystalline product (2) that was shown by elemental analysis to have a 1:1 metal:ligand ratio. ${ }^{1} \mathrm{H}$ NMR, infrared and 
mass spectra were all recorded and are given in the experimental section. The ${ }^{1} \mathrm{H}$ NMR spectrum showed small downfield shifts $(+0.18-0.01 \mathrm{ppm})$ of the pyridine ring protons relative to the free ligand in the same solvent, consistent with silver coordination to this ring nitrogen. The structure of 2 was unambiguously determined by X-ray crystallography.

This compound crystallises in the orthorhombic space group $\mathrm{P} 2{ }_{1} 2_{1} 2_{1}$. Figure 1 shows a perspective view, with selected atom labelling, of the contents of the asymmetric unit, which contains a silver atom, a molecule of nicotine and a coordinated nitrate anion. The absolute configuration of the nicotine was known to be $(\mathrm{S})$ and was confirmed by refinement of the Flack parameter [61]. The nicotine uses both of its available nitrogen atoms to bridge two silvers, which are four coordinate with highly distorted tetrahedral angles in the range 85.22(6) 127.85(7) ${ }^{\circ}$. Each silver is bonded to both a pyridine and a pyrrolidine nitrogen of two different nicotine molecules and to two different nitrate oxygens. Thus, nicotine molecules act as bridges to form polymeric chains which are cross-linked by the nitrate groups, which also act as bridging ligands and hence extend the polymeric structure into a three-dimensional network, a small section of which is shown in Figure 2. Silver atoms bridged by the nicotine molecules are separated by $7.886 \AA$, while those bridged by nitrate anions are $5.715 \AA$ apart.

[Figures 1 and 2 here]

Reaction of silver nitrate with three equivalents of nicotine furnished another crystalline product (3) that was shown by elemental analysis to have a 1:2 metal:ligand ratio. In this case only very small shifts of the pyridine ring protons were observed in the ${ }^{1} \mathrm{H}$ NMR spectrum. This compound crystallises in the monoclinic space group $\mathrm{P} 2_{1}$. Figure 3 shows the contents of the asymmetric unit which comprises one silver atom, two nicotine molecules and a monodentate nitrate anion. The silver atom is again four coordinate with a distorted tetrahedral geometry having angles within the range $91.01(7)-120.76(8)^{\circ}$. It is bonded to three nicotine molecules, two via the pyridine nitrogen and one via the pyrrolidine nitrogen, and to an oxygen atom of the nitrate. The extended structure consists of a one-dimensional polymer in which half of the nicotine molecules are bridging and the others are hypodentate (i.e. the amine nitrogen is not coordinated). These polymer chains propagate along the $b$-axis of the unit cell by means of the crystallographic two-fold screw axis, with silver-silver separations of $8.019 \AA$. As shown in Figure 4, the pendant monodentate nicotine molecules interdigitate into cavities within the adjacent polymer chain in the $\mathrm{z}$-direction. 
[Figures 3 and 4 here]

A third crystalline complex (4) was obtained by the reaction of silver(I) tetrafluoroborate with one equivalent of nicotine and was shown by elemental analysis to have a 1:1 metal:ligand ratio. This also crystallises in the monoclinic space group $\mathrm{P} 2_{1}$ and has a silver atom, a nicotine molecule, two coordinated acetonitrile molecules and a disordered tetrafluoroborate anion in the asymmetric unit (Figure 5). Once again, the silver has a distorted tetrahedral geometry with angles in the range $86.5(1)-127.9(1)$. The nicotine molecules bridge two silver atoms (related by translation along the $a$ axis) to form a linear one-dimensional coordination polymer (Figure 6 ), which is similar to chains present in the structure of 2 , but with the coordinated acetonitriles replacing the nitrates. However, since the acetonitrile molecules are unable to act as bridges, there is no cross-linking of the chains into a higher-dimensional network. The separation between adjacent silver atoms is $7.602 \AA$, the length of the $a$ axis. The non-coordinating tetrafluoroborate anions occupy the voids between the polymers chains.

[Figures 5 and 6 here]

In all three structures the conformations of the bridging nicotine molecule are very similar. The pyrrolidine ring exists in an envelope conformation with the nitrogen atom $c a .0 .7 \AA$ out of the plane of the ring carbon atoms. The silver atoms coordinate to these nitrogens from the same side of the plane as the adjacent pyridyl substituent, thereby occupying a pseudo-axial orientation. The planes of the pyridyl rings are inclined to the planes of the pyrolidine rings at angles in the range $60-72^{\circ}$. The conformation of the hypodentate nicotine in complex 3 , differs slightly, with the pyrrolidine nitrogen only $0.60 \AA$ out of plane and the rings at an angle of $83^{\circ}$.

\section{CONCLUSION}

$(S)-(-)$-Nicotine has indeed been shown to act as a useful bridging ligand for the formation of chiral coordination polymers. Due to the two very different binding domains this bidentate ligand faithfully aligns itself in a regular fashion in the formation of these polymeric products. A desirable feature of chiral coordination polymers is that of directionality [31] as this can amplify NLO properties. The asymmetric nature of $(S)-(-)$-nicotine along with its two different binding sites could lead to highly directional coordination polymers. However, complex $\mathbf{2}$ has three orthogonal two-fold screw axes and a three-dimensional network structure. Complexes $\mathbf{3}$ and $\mathbf{4}$ are both one-dimensional coordination polymers with only one two-fold screw axis. In complex 
4 this screw axis relates adjacent polymer chains (which propagate by translation along the $a$ axis), thereby reducing the overall degree of directionality within the crystal. However, in complex 3 adjacent chains are related by translation and the screw axis generates the polymer chains. This leads to a chiral coordination polymer with a high degree of directionality.

\section{EXPERIMENTAL SECTION}

\section{General Remarks}

Melting points were recorded on an Electrothermal melting point apparatus and are uncorrected. The Campbell microanalytical laboratory at the University of Otago performed elemental analyses. Electrospray (ES) mass spectra were recorded using a Micromass LCT-TOF mass spectrometer. NMR spectra were recorded on a Varian $500 \mathrm{MHz}$ spectrometer at $23^{\circ} \mathrm{C}$, using a 3 $\mathrm{mm}$ probe. IR spectra were recorded with a Shimadzu FTIR-8201PC spectrophotometer. All reagents and reactants were obtained from commercial sources and used as received.

\section{Syntheses}

\section{[(S)-(-)-Nicotine]-nitrato-silver(I) (Complex 2)}

A solution of nicotine in acetonitrile $(0.4 \mathrm{M}, 1 \mathrm{~mL})$ was added to a solution of silver nitrate $(66 \mathrm{mg}, 0.4 \mathrm{mmol})$ in acetonitrile $(1 \mathrm{~mL})$. A crystalline product was obtained by the diffusion of diethyl ether into the solution. Yield $74 \mathrm{mg}$ (56\%). M.p. $149-151{ }^{\circ} \mathrm{C}$ (dec.). ${ }^{1} \mathrm{H}-\mathrm{NMR}(500 \mathrm{MHz}$, $\left.\mathrm{CD}_{3} \mathrm{CN}\right): \delta 8.70(1 \mathrm{H}, \mathrm{d}, \mathrm{H} 2), 8.55(1 \mathrm{H}, \mathrm{dd}, \mathrm{H} 6), 7.99(1 \mathrm{H}, \mathrm{dt}, \mathrm{H} 5), 7.56(1 \mathrm{H}, \mathrm{dd}, \mathrm{H} 4), 3.37-$ 3.41 (1H, m, H7), 3.31 (1H, t, H9a), 2.45-2.50 (1H, m, H9b), 2.33-2.39 (1H, m, H11a), 2.32 (s, 3H, $\left.\mathrm{NCH}_{3}\right), 2.05-2.11(1 \mathrm{H}, \mathrm{m}, \mathrm{H} 10 \mathrm{a}), 1.94-2.00$ (1H, m, H10b), 1.87-1.91 (1H, m, H1 1b). IR (KBr mull): 2967, 2871, 2797, 2398, 1753, 1597, 1388, 899, 807, $714 \mathrm{~cm}^{-1}$. ES-MS: Found $\mathrm{M}^{+}$600.0, $\left.\left[\mathrm{Ag}_{2} \text { (nicotine) }\right)_{2}\left(\mathrm{NO}_{3}\right)\right]^{+}$requires $\mathrm{M}^{+}$600.0, found $\mathrm{M}^{+}$431.1, $\left[\mathrm{Ag}(\text { nicotine })_{2}\right]^{+}$requires $\mathrm{M}^{+}$431.1, found $\mathrm{M}^{+}$310.0, [Ag(nicotine) $\left.\left(\mathrm{CH}_{3} \mathrm{CN}\right)\right]^{+}$requires $\mathrm{M}^{+}$310.0. Anal. Found: $\mathrm{C}, 35.98$; $\mathrm{H}, 4.29 ; \mathrm{N}, 12.91$. Calc for $\mathrm{C}_{10} \mathrm{H}_{14} \mathrm{~N}_{3} \mathrm{O}_{3} \mathrm{Ag}$ : C, 36.17; H, 4.25; N, 12.65 .

\section{Bis-[(S)-(-)-Nicotine]-nitrato-silver(I) (Complex 3)}

A solution of nicotine in acetonitrile $(0.4 \mathrm{M}, 3 \mathrm{~mL})$ was added to silver nitrate $(66 \mathrm{mg}, 0.4 \mathrm{mmol})$ dissolved in acetonitrile $(4 \mathrm{~mL})$. A crystalline product was obtained by the diffusion of diethyl ether into the solution. Yield $146 \mathrm{mg}$ (74\%). M.p. $141-142^{\circ} \mathrm{C}$ (dec.). ${ }^{1} \mathrm{H}$ NMR (300 MHz, 
$\left.\mathrm{CDCl}_{3}\right): \delta 8.69(1 \mathrm{H}, \mathrm{s}, \mathrm{H} 2), 8.54(1 \mathrm{H}, \mathrm{d}, \mathrm{H} 6), 7.82-7.85(1 \mathrm{H}, \mathrm{m}, \mathrm{H} 5), 7.36-7.40(1 \mathrm{H}, \mathrm{m}, \mathrm{H} 4)$, 3.48 (1H, s, H7), 3.35 (1H, t, H9a), 3.16 (1H, t, H9b), 2.20-2.42 (1H, m, H11a), 2.26 (3H, s, $\mathrm{NCH}_{3}$ ), 1.97-2.01 (1H, m, H10a), 1.81-1.86 (2H, m, H10b,H11b). IR (KBr mull): 2976, 2770, 1762, 1576, 1390, 1035, 903, 807, $716 \mathrm{~cm}^{-1}$. Anal. Found: C, 48.78; H, 5.70; N, 14.27. Calc for $\left.\mathrm{C}_{20} \mathrm{H}_{28} \mathrm{~N}_{5} \mathrm{O}_{3} \mathrm{Ag}: \mathrm{C}, 48.59 ; \mathrm{H}, 5.71 ; \mathrm{N}, 14.17\right)$.

\section{Bis-(acetonitrile-)[(S)-(-)-Nicotine]-silver(I) Tetrafluoroborate (Complex 4)}

A solution of nicotine in acetonitrile $(0.4 \mathrm{M}, 1 \mathrm{~mL})$ was added to silver tetrafluoroborate $(78 \mathrm{mg}$, $0.4 \mathrm{mmol})$ dissolved in acetonitrile $(2 \mathrm{~mL})$. A crystalline product was obtained by the diffusion of ethyl acetate into the solution. Yield $126 \mathrm{mg}$ (72\%). M.p. $135-140^{\circ} \mathrm{C}$ (dec.). IR ( $\mathrm{KBr}$ mull): 2943, 2781, 1578, 1427, 1315, 1042(br), 905, 808, 718, 534, $523 \mathrm{~cm}^{-1}$. Anal. Found: C, 33.66; $\mathrm{H}, 4.28 ; \mathrm{N}, 7.81$. Calc for $\mathrm{C}_{10} \mathrm{H}_{14} \mathrm{BF}_{4} \mathrm{~N}_{2} \mathrm{Ag}$ : C, 33.65; H, 3.95; N, 7.85 .

\section{X-Ray Crystallography}

The crystal data, data collection and refinement parameters are listed in Table 1. Data were collected with a Siemens SMART CCD area detector, using graphite monochromatized MoKa radiation $(\lambda=0.71073 \AA)$. The intensities were corrected for Lorentz and polarisation effects and for absorption [62]. The structures were solved by direct methods using SHELXS [63] and refined on $\mathrm{F}^{2}$, using all data, by full-matrix least-squares procedures using SHELXTL [64]. All non-hydrogen atoms were refined with anisotropic displacement parameters. Hydrogen atoms were included in calculated positions, with isotropic displacement parameters 1.2 times the isotropic equivalent of their carrier carbons (or 1.5 times for methyl hydrogens).

Full tables of atom coordinates, thermal parameters, and bond lengths and angles have been deposited at the Cambridge Crystallographic Data Centre. CCDC 272326 - 272328 contains the supplementary crystallographic data for this paper. These data can be obtained free of charge at www.ccdc.cam.ac.uk/conts/retrieving.html [or from the Cambridge Crystallographic Data Centre, 12 Union Road, Cambridge CB2 1EZ, UK; fax: (internat.) + 441223/336-033; Email: deposit@ccdc.cam.ac.uk].

\section{Acknowledgements}

We thank the Royal Society of New Zealand Marsden Fund for financial support. 


\section{References}

[1] Constable, E. C. Chem. Ind., 1994, 56-59; Steel, P. J. Chemistry in New Zealand 2003, 67, 57-60.

[2] Hagrman, P. J.; Hagrman, D.; Zubieta, J. Angew. Chem., Int. Ed. 1999, 38, 2638-2684.

[3] Braga, D.; Grepioni, F.; Desiraju, G. R. Chem. Rev. 1998, 98, 1375-1406.

[4] Batton, S. R. Curr. Opin. Solid State Mater. Sci. 2001, 5, 107-114.

[5] Hosseini, M. W. Acc. Chem. Res. 2005, 38, 313-323.

[6] Munakata, M.; Wu, L. P.; Kuroda-Sowa, T. Adv. Inorg. Chem. 1999, 46, 173-304.

[7] Khlobystov, A. N.; Blake, A. J.; Champness, N. R.; Lemenovskii, D. A.; Majouga, A. G.; Zyk, N. V.;Schroder, M. Coord. Chem. Rev. 2001, 222, 155-192.

[8] Moulton, B.; Zaworotko, M. J. Chem. Rev. 2001, 101, 1629-1658.

[9] Eddaoudi, M.; Moler, D. B.; Li, H.; Chen, B.; Reineke, T. M.; O'Keeffe, M.; Yaghi, O. M. Acc. Chem. Res. 2001, 34, 319-330.

[10] James, S. L. Chem. Soc. Rev. 2003, 32, 276-288.

[11] Barnett, S. A.; Champness, N. R. Coord. Chem. Rev. 2003, 246, 145-168.

[12] Oh, M.; Carpenter, G. B.; Sweigart, D. A. Acc. Chem. Res. 2004, 37, 1.

[13] Férey, G.; Mellot-Draznieks, C.; Serre, C.; Millange F. Acc. Chem. Res. 2005, 38, 217225.

[14] Batten, S. R.; Robson, R. Angew. Chem., Int. Ed. 1998, 37, 1461-1494.

[15] Robson, R. J. Chem. Soc., Dalton Trans. 2000, 3735-3744.

[16] Carlucci, L.; Ciani, G.; Proserpio, D. M. Coord. Chem. Rev. 2003, 246, 247-289.

[17] Bradshaw, D.; Claridge, J. B.; Cussen, E. J.; Prior, T. J.; Rosseinsky, M. J. Acc. Chem. Res. 2005, 38, 273-282.

[18] Hill, R. J.; Long, D.; Champness, N. R.; Hubberstey, P.; Schröder, M. Acc. Chem. Res. 2005, 38, 335-348.

[19] Janiak, C. Dalton Trans. 2003, 2781-2803.

[20] Kitagawa, S.; Kitaura, R.; Noro, S. Angew. Chem., Int. Ed. 2004, 43, 2334-2375.

[21] Papaefstathiou, G. S.; MacGillivray, L. R. Coord. Chem. Rev. 2003, 246, 169-184.

[22] Evans, O. R.; Lin, W. Acc. Chem. Res. 2002, 35, 511-522.

[23] Evans, O. R.; Lin, W. Chem. Mater. 2001, 13, 2705-2712.

[24] Lin, W.; Ma, L.; Evans, O. R. Chem. Commun. 2000, 2263-2264.

[25] Evans, O. R.; Lin, W. Chem. Mater. 2001, 13, 3009-3017.

[26] Lin, W.; Wang, Z.; Ma, L. J. Am. Chem. Soc. 1999, 121, 11249-11250. 
[27] Evans, O. R.; Lin, W. J. Chem. Soc., Dalton Trans. 2000, 21, 3949-3954.

[28] Chen, J.; MacDonnell, F. M. Chem. Commun. 1999, 2529-2530.

[29] Bernhard, S.; Takada, K.; Diaz, D. J.; Abruna, H. D.; Murner, H. J. Am. Chem. Soc. 2001, $123,10265-10271$.

[30] Ma, S.; Wu. S. New J. Chem. 2001, 25, 1337-1341.

[31] Jouaiti, A.; Hosseini, M. W.; Kyritsakas, N. Chem. Commun. 2002, 1898-1899.

[32] Mamula, O.; von Zelewsky, A. Coord. Chem. Rev. 2003, 242, 87-95.

[33] Wu, C.-D.; Ngo, H. L.; Lin, W. Chem. Commun. 2004, 1588-1589.

[34] Wang, R.; Xu, L.; Li, Y.; Shi, Q.; Zhou, Z.; Hong, M.; Chan, A. S. C. Eur. J. Inorg. Chem. 2004, 1595-1599.

[35] Xiong, R.-G.; Zuo, J.-L.; You, X.-Z. Fun, H.-K.; Raj, S. S. S. New J. Chem. 1999, 23, 1051-1052.

[36] Xie, Y.-R.; Xiong, R.-G.; Xue, X.; Chen, X.-T.; Xue, Z.; You, X.-Z. Inorg. Chem. 2002, $41,3323-3326$.

[37] Zaworotko, M. J. Angew. Chem., Int. Ed. 1998, 37, 1211-1213.

[38] Caradoc-Davies, P. L.; Hanton, L. R. Chem. Commun. 2001, 1098-1099.

[39] Shi, Z.; Feng, S.; Sun, Y.; Hua, J. Inorg. Chem. 2001, 40, 5312-5313.

[40] Kalra, M. K.; Zhang, H.; Son, D. Y. Inorg. Chem. Commun. 2004, 7, 1019-1022.

[41] Han, L.; Hong, M. Inorg. Chem. Commun. 2005, 8, 406-419.

[42] Kondo, M.; Miyazawa, M.; Irie, Y.; Shinagawa, R.; Horiba, T.; Nakamura, A.; Naito, T.; Maeda, K.; Utsuno, S.; Uchida, F. Chem. Commun. 2002, 2156-2157.

[43] Sporer, C.; Wurst, K.; Amabilino, D. B.; Ruiz-Molina, D.; Kopacka, H.; Jaitner, P.; Veciana, J. Chem. Commun. 2002, 2342-2343.

[44] Siemeling, U.; Scheppelmann, I.; Neumann, B.; Stammler, A.; Stammler, H.-G.; Frelak, J. Chem. Commun. 2003, 2236-2237.

[45] Gao, E.-Q.; Yue, Y.-F.; Bai, A.-Q.; He, Z.; Yan, C.-H. J. Am. Chem. Soc. 2004, 126, 1419-1429.

[46] Fitchett, C. M.; Steel, P. J. New J. Chem. 2000, 24, 945-947.

[47] Downard, A. J.; Phillips, I. G.; Steel. P. J. Aust. J. Chem. 2004, 57, 865-868.

[48] Steel, P. J. Acc. Chem. Res. 2005, 38, 243-250.

[49] Steel, P. J. Molecules 2004, 9, 440-448.

[50] Guan, J.; Fischer, R. D. Eur. J. Inorg. Chem. 2001, 10, 2497-2508.

[51] Gillard, R. D.; Lekkas, E. Transition Met. Chem. 2000, 25, 617-621. 
[52] Peulecke, N.; Lefeber, C.; Ohff, A.; Baumann, W.; Tillack, A.; Kempe, R.; Burlakov, V. V.; Rosenthal, U. Chem. Ber. 1996, 128, 959-962.

[53] Gillard, R. D.; Pedrosa de Jesus, J. D.; Mohamed, A. Y. A.; Transition Met. Chem. 1989, $14,258-260$.

[54] Haendler, H. M. Acta Crystallogr. Sect. C, 1990, C46, 2054-2057.

[55] Smith, C. R. J. Am. Chem. Soc., 1953, 75, 2010-2012.

[56] Smith, C. R. J. Am. Chem. Soc., 1949, 71, 2844-2846.

[57] Udupa, M. R.; Krebs, B. Inorg. Chim. Acta 1980, 40, 161-164.

[58] McMorran, D. A.; Steel, P. J. Supramolecular Chem. 2002, 14, 79-85.

[59] Richardson, C.; Steel, P. J. Eur. J. Inorg. Chem. 2003, 405-408, and references therein.

[60] Sumby, C. J.; Steel, P. J. New J. Chem. 2005, 29, 1077-1081.

[61] Flack, H. D.; Bernardinelli, G. J. Appl. Crystallogr. 2000, 33, 1143-1148.

[62] Sheldrick, G. M. SADABS, University of Göttingen, Germany, 1998.

[63] Sheldrick, G. M. Acta Crystallogr. Sect. A 1990, 46, 467-473.

[64] Sheldrick, G. M. SHELXTL; Bruker Analytical X-ray Systems, 1997. 


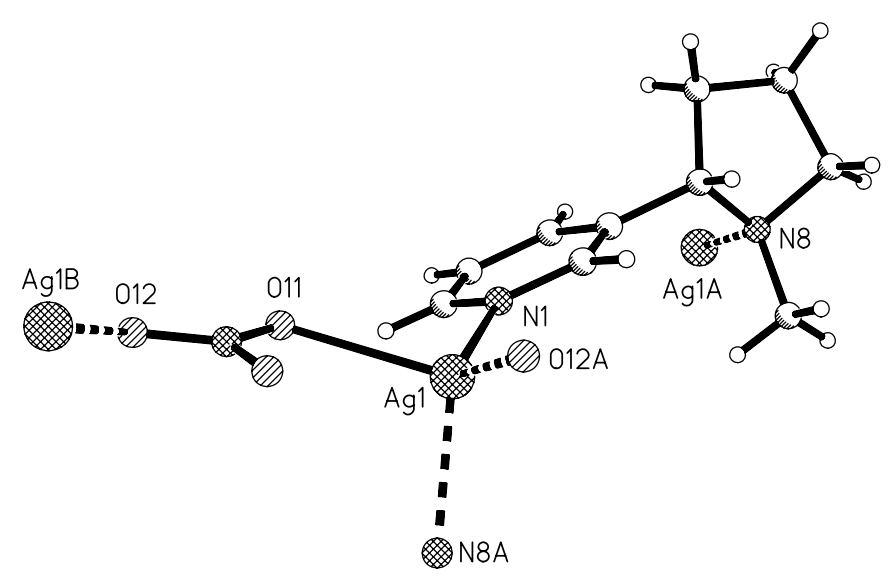

Figure 1. Perspective view of the contents of the asymmetric unit, and attached atoms, in the Xray structure of 2 . Selected bond lengths $(\AA)$ and angles $\left({ }^{\circ}\right)$ : Ag1-N1 2.3007(19); Ag1-N8A 2.3806(17); Ag1-O11 2.5789(19); Ag1-O12A 2.4509(18); N1-Ag1-N8A 125.35(6); N1-Ag1O11 85.22(6); N1-Ag1-O12A 127.86(7); N8A-Ag1-O11 102.81(7); N8A-Ag1-O12A 92.48(7); O11-Ag1-O12A 123.47(7).

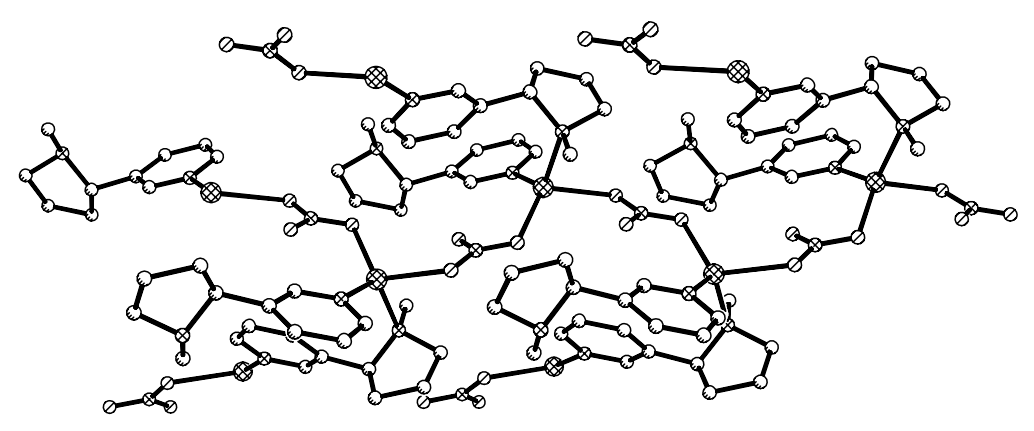

Figure 2. Perspective view, down the $c$ axis, of a section of the extended structure of 2. Hydrogen atoms are omitted for clarity. 


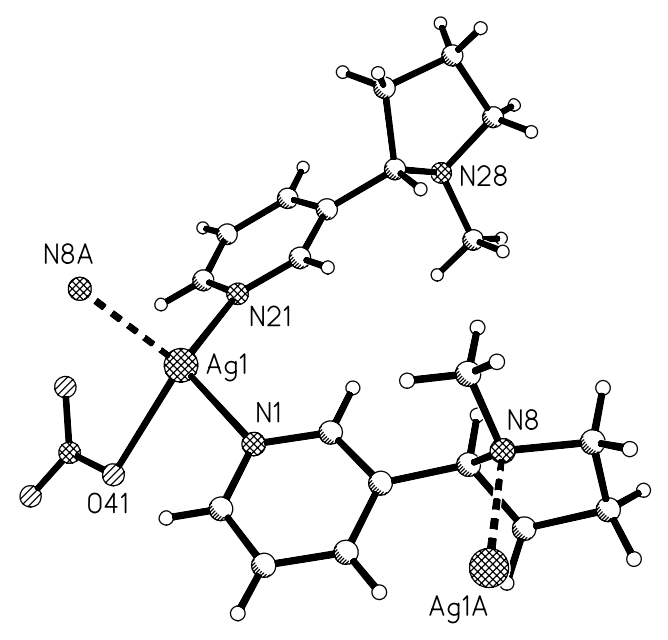

Figure 3. Perspective view of the contents of the asymmetric unit, and attached atoms, in the Xray structure of 3. Selected bond lengths $(\AA)$ and angles $\left({ }^{\circ}\right)$ : Ag1-N1 2.323(2); Ag1-N8A 2.405(2); Ag1-N21 2.298(2); Ag1-O41 2.500(2); N1-Ag1-N8A 117.93(7); N1-Ag1-N21 120.14(8); N1-Ag1-O41 91.01(7); N8A-Ag1-N21 106.76(8); N8A-Ag1-O41 103.19(7); N21Ag1-O41 116.05(8).

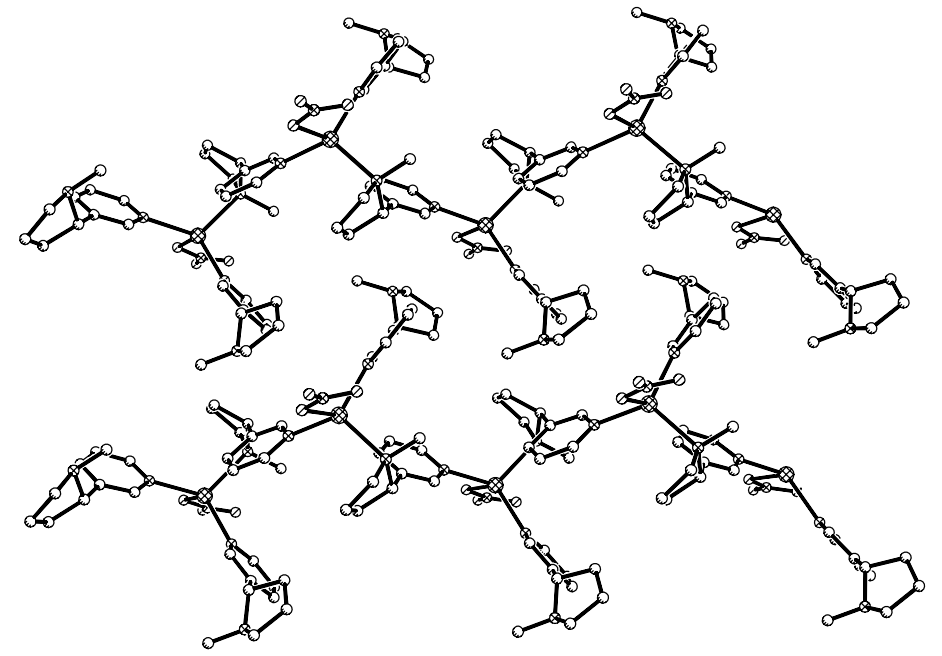

Figure 4. Perspective view, down the $a$ axis, of the extended structure of 3 . Hydrogen atoms are omitted for clarity. 


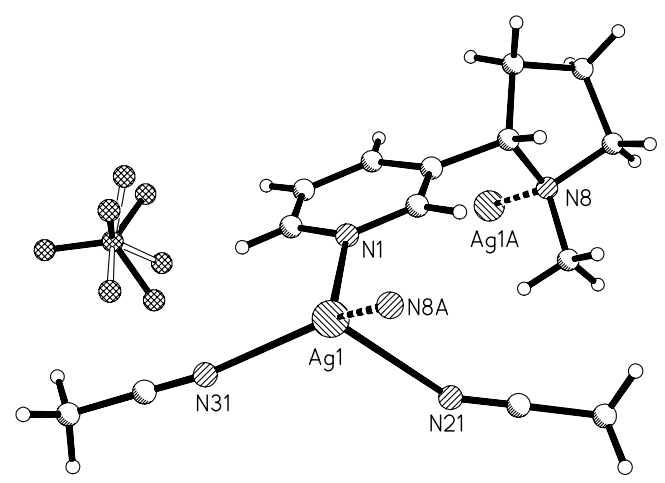

Figure 5. Perspective view of the contents of the asymmetric unit, and attached atoms, in the Xray structure of 4 . Selected bond lengths $(\AA)$ and angles $\left(^{\circ}\right)$ : Ag1-N1 2.334(3); Ag1-N8A 2.326(3); Ag1-N21 2.572(4); Ag1-N31 2.329(3); N1-Ag1-N8A 127.93(9); N1-Ag1-N21 86.49(11); N1-Ag1-N31 99.70(11); N8A-Ag1-N21 94.54(12); N8A-Ag1-N31 126.3(1); N21Ag1-N31 113.75(13).

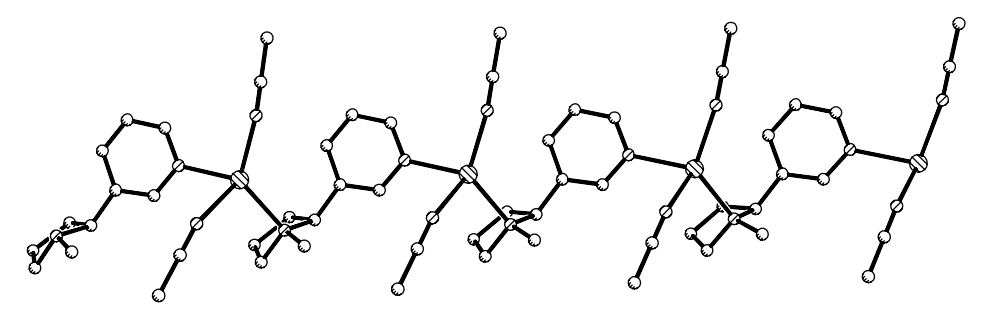

Figure 6. Perspective view of the extended structure of the one-dimensional coordination polymer 4 . The hydrogen atoms and non-coordinated tetrafluoroborate anions are not shown. 
TABLE 1. Crystal data and refinement parameters.

\begin{tabular}{|l|l|l|l|}
\hline Compound & $\mathbf{2}$ & $\mathbf{3}$ & $\mathbf{4}$ \\
\hline Formula & $\mathrm{C}_{10} \mathrm{H}_{14} \mathrm{~N}_{3} \mathrm{O}_{3} \mathrm{Ag}$ & $\mathrm{C}_{20} \mathrm{H}_{28} \mathrm{~N}_{5} \mathrm{O}_{3} \mathrm{Ag}$ & $\mathrm{C}_{14} \mathrm{H}_{20} \mathrm{BF}_{4} \mathrm{~N}_{4} \mathrm{Ag}$ \\
\hline Formula weight & 332.11 & 494.34 & 439.02 \\
\hline $\mathrm{T} / K$ & $170(2)$ & $168(2)$ & $168(2)$ \\
\hline Crystal Size/mm & $0.50 \times 0.35 \times 0.30$ & $0.42 \times 0.21 \times 0.13$ & $0.50 \times 0.40 \times 0.20$ \\
\hline Crystal System & orthorhombic & monoclinic & monoclinic \\
\hline Space Group & $\mathrm{P} 2{ }_{1} 2{ }_{1}{ }_{1}$ & $\mathrm{P}{ }_{1}$ & $\mathrm{P} 2{ }_{1}$ \\
\hline$a / \AA$ & $9.925(2)$ & $9.376(3)$ & $7.602(4)$ \\
\hline$b / \AA$ & $11.276(2)$ & $11.393(3)$ & $11.134(5)$ \\
\hline$c / \AA$ & $11.284(2)$ & $10.262(3)$ & $11.034(5)$ \\
\hline$\beta /{ }^{\circ}$ & 90 & $94.509(4)$ & $90.352(6)$ \\
\hline$V / \AA^{3}$ & $1262.8(4)$ & $1092.9(6)$ & $933.9(8)$ \\
\hline$Z$ & 4 & 2 & 2 \\
\hline$\rho_{\text {calc }} / \mathrm{g}$ cm & & & 1.561 \\
\hline$\mu /$ mm $^{-1}$ & 1.747 & 1.502 & 1.119 \\
\hline $2 \theta$ max/ & 1.597 & 0.952 & 52.792 \\
\hline Total reflections & 54.396 & 52.756 & 11193 \\
\hline Unique refls. $\left[\mathrm{R}_{\text {int }}\right]$ & $2475[0.0199]$ & $4388[0.0229]$ & $3652[0.0212]$ \\
\hline Refls. $I>2 \sigma(I)$ & 2458 & 3998 & 3578 \\
\hline Parameters & 155 & 264 & 248 \\
\hline GOOF & 1.101 & 0.979 & 1.064 \\
\hline Completeness $(\%)$ & 99.7 & 99.9 & 98.9 \\
\hline$R[F, I>2 \sigma(I)]$ & 0.0160 & 0.0212 & 0.0297 \\
\hline$w R\left(F^{2}\right.$, all data $)$ & 0.0410 & 0.0466 & 0.0771 \\
\hline & & & \\
\hline
\end{tabular}




\section{Graphical Abstract}

Chiral heterocyclic ligands. XI. Self-assembly and X-ray crystal structures of chiral silver coordination polymers of (S)-(-)-nicotine.

William Lewis and Peter J. Steel*

Chemistry Department, University of Canterbury, Christchurch 8020, New Zealand

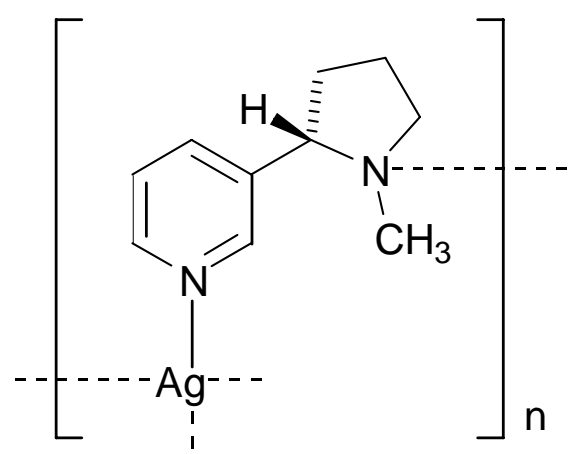

